Short communication

\title{
Mitral and aortic valve endocarditis together with mitral cleft developing due to an incorrectly inserted permanent hemodialysis catheter
}

\author{
Oktay Şenöz ${ }^{a}$, Sadık Volkan Emren ${ }^{\text {b,* }}$ \\ a Artvin State Hospital, Department of Cardiology, Artvin, Turkey \\ b Afyonkarahisar State Hospital, Department of Cardiology, Afyonkarahisar, Turkey
}

\section{A R T I C L E I N F O}

\section{Article history:}

Received 27 June 2015

Received in revised form 15 July 2015

Accepted 15 July 2015

Available online 25 September 2015

\section{Keywords:}

Infective endocarditis

Hemodialysis catheter

Echocardiography

\begin{abstract}
A B S T R A C T
Infective endocarditis (IE) usually affects the right-sided valves in hemodialysis (HD) patients. Hemodialysis catheter-related left-sided endocarditis is a very rare condition and has a high mortality. A 58-year-old male patient who had been inserted a permanent HD catheter from the right subclavian vein 6 months ago was admitted with fever and dyspnea. Transesophageal echocardiography (TEE) revealed that the HD catheter extended to the left atrium by passing from interatrial septum (IAS). A vegetation in the interatrial septum, aortic valve, which formed a perforation in the mitral valve and leading to severe valve insufficiency was observed. The patient was planned to undergo an operation however he died as a result of impaired hemodynamic stability. Catheter site should be confirmed through an imaging method performed during or after the procedure in order to prevent catheter malposition. A proper antibiotic treatment should be started as soon as a catheter-related endocarditis is detected, a surgical decision should be done in the shortest and the most proper time.

(C) 2015 The Society of Cardiovascular Academy. Production and hosting by Elsevier B.V. All rights reserved. This is an open access article under the CC BY-NC-ND license (http://creativecommons.org/licenses/by-nc-nd/4.0/).
\end{abstract}

\section{Introduction}

Although IE is a rare condition in general population, its prevalence is quite higher in HD patients. ${ }^{1}$ Catheter-related infection is the most important cause of IE in HD patients. ${ }^{2}$ Although HD catheter-related right-sided endocarditis is relatively frequent, left-sided endocarditis is quite rare and usually develops as a result of the right-sided infected catheter's affecting the left-sided valves through septicemia. ${ }^{3}$ Another rare cause not reported before is the HD catheter's passing from IAS to the left side and directly affecting the valves.

In this paper, a patient who was inserted a permanent HD catheter through the subclavian vein 6 months ago, in whom echocardiography performed due to fever and dyspnea revealed aortic valve endocarditis together with mitral perforation developing due to the HD catheter's passing from IAS to the left atrium is presented.

\section{Case presentation}

A 58-year-old male patient was admitted to the emergency room with complaints of dyspnea, fever, night sweating and loss of appetite lasting for 3 weeks. On his medical history, he had hypertension,

\footnotetext{
* Corresponding author. Tel.: +90 5052644578; fax: +90 2722147575

E-mail addresses: oktaysenoz@hotmail.com (0. Şenöz), vemren@hotmail.com (S.V. Emren).

Peer review under responsibility of The Society of Cardiovascular Academy.
}

coronary artery disease and chronic renal failure. The patient who had been enrolled in HD program 6 months ago had been inserted a permanent HD catheter from the right subclavian vein. On his physical examination, arterial blood pressure was $110 / 50 \mathrm{~mm} \mathrm{Hg}$, heart rate was $130 \mathrm{bpm}$, rhythmic, fever was $38.6{ }^{\circ} \mathrm{C}$, on cardiac examination, S1 and S2 were normal, there was $4 / 6$ pansystolic murmur on apical focus and 3/6 diastolic murmur in aortic focus. Respiratory sounds were heard on lung examination. Pathologic lung sounds were heard on the inferior part of the right lung. Laboratory findings were as follows: WBC $21,000 / \mathrm{mm}^{3}$, hemoglobin $9.5 \mathrm{~g} / \mathrm{dl}$, hematocrit $29 \%$, platelet count $226,000 / \mathrm{mm}^{3}$, urea $86 \mathrm{mg} / \mathrm{dl}$, creatinine $4.8 \mathrm{mg} / \mathrm{dl}$, aspartate aminotransferase (AST) $96 \mathrm{IU} / \mathrm{lt}$, alanine aminotransferase (ALT) $89 \mathrm{IU} / \mathrm{lt}$, total bilirubin $5.9 \mathrm{mg} / \mathrm{dl}$, direct bilirubin $5.1 \mathrm{mg} / \mathrm{dl}$, C-reactive protein (CRP) $36 \mathrm{mg} / \mathrm{dl}$, and erythrocyte sedimentation rate (ESR) $80 \mathrm{~mm} / \mathrm{h}$. Computed tomography of thorax revealed bilateral pleural effusion and consolidation suggestive for a pneumonic infiltration in the inferior zone of the right lung. Intravenous moxifloxacin $400 \mathrm{mg}$ daily treatment was started with diagnosis of community-acquired pneumonia. Treatment was switched to piperacillin-tazobactam as fever continued for $48 \mathrm{~h}$ despite antibiotic treatment. Transthoracic echocardiography was performed with prediagnosis of infective endocarditis due to the presence of a permanent HD catheter, persistent fever and diastolic and systolic murmur on physical examination. On echocardiography, ejection fraction was $60 \%$, an appearance of a hyperechogenic catheter density was observed which was directed from superior vena cava to IAS and extending to pulmonary veins in the left atrium. Transesophageal echocardiography (TEE) was performed as vegetation appearance 


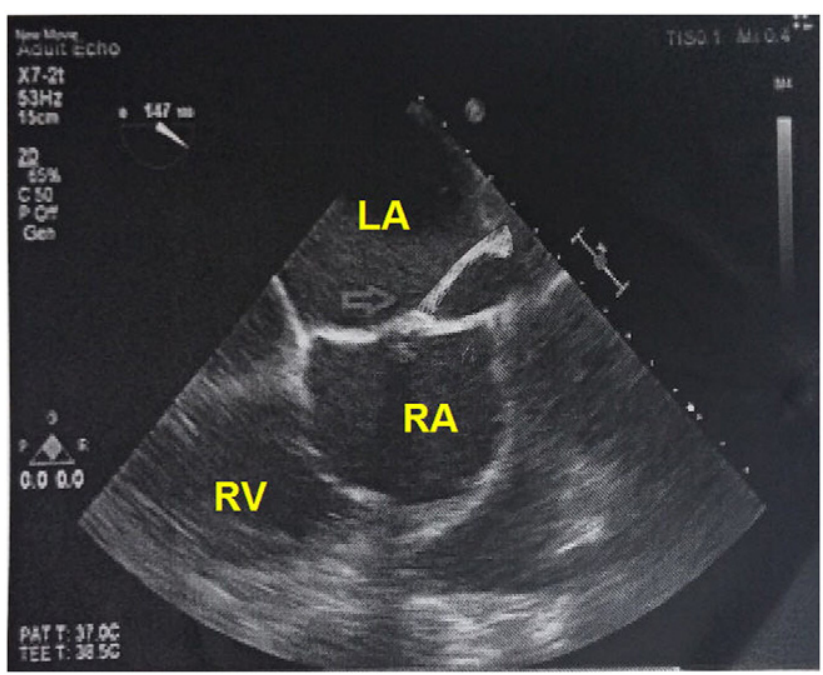

Fig. 1. The tip of the catheter was detected to pass from patent foramen ovale in transesophageal echocardiography (TEE).

was observed on the catheter and mitral valve and size of the vegetation was tried to be determined. On TEE, a mobile, multiple, filamentous heterogeneous density was observed on the catheter in the right atrium. The tip of the catheter was detected to pass from patent foramen ovale (PFO) which was a short tunnel in IAS and extend to pulmonary veins from the left atrium (Fig. 1). A mobile vegetation in heterogeneous density, measuring $1.2 \times 1.4 \mathrm{~cm}^{2}$ was observed on the anterior leaflet of the mitral valve (Fig. 2). Beside, a vegetation image measuring $0.8 \times 0.6 \mathrm{~cm}^{2}$ was observed on non-coronary cuspis of the aortic valve (Fig. 2). A defect consistent with a perforation due to the destruction of the vegetation which causes a second jet on the anterior leaflet of the mitral valve was observed in addition to the severe central mitral insufficiency (Fig. 3). There was no defect on papillary muscles or the chords. The ends of all three cuspis were extremely irregular, calcified and there was moderate tricuspid insufficiency and systolic pulmonary artery pressure was measured as $60 \mathrm{~mm} \mathrm{Hg}$. Vegetation was not observed in the tricuspid valve and pulmonary valve. Meticillin-sensitive staphylococcus aureus (MSSA) grew in two blood cultures. Antibiotic treatment was arranged as cefazolin $1 \mathrm{~g}$ once daily and gentamicin $0.5 \mathrm{mg} / \mathrm{kg}$ bid. Early surgical operation was planned under antibiotic treatment due to severe mitral insufficiency. However hemodynamic

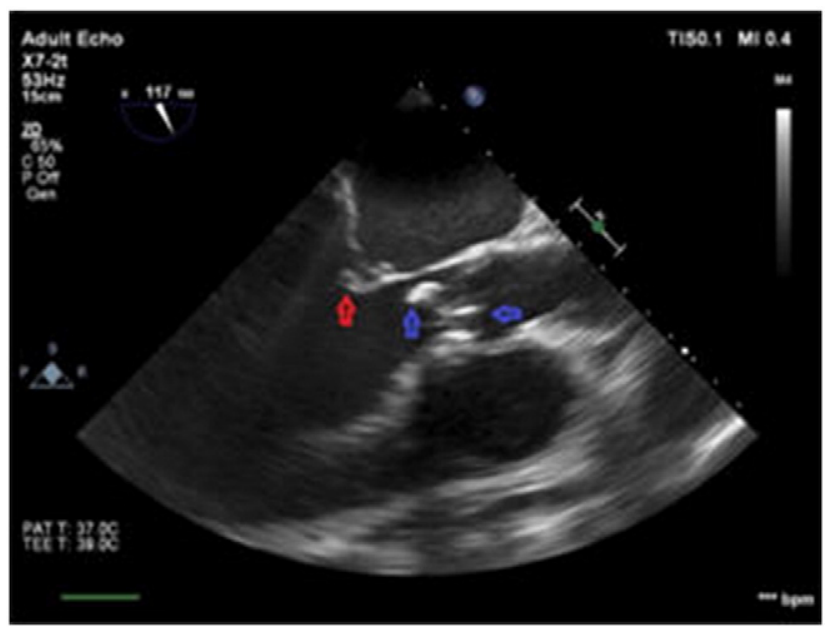

Fig. 2. The vegetations are present in both the mitral and aortic valves.

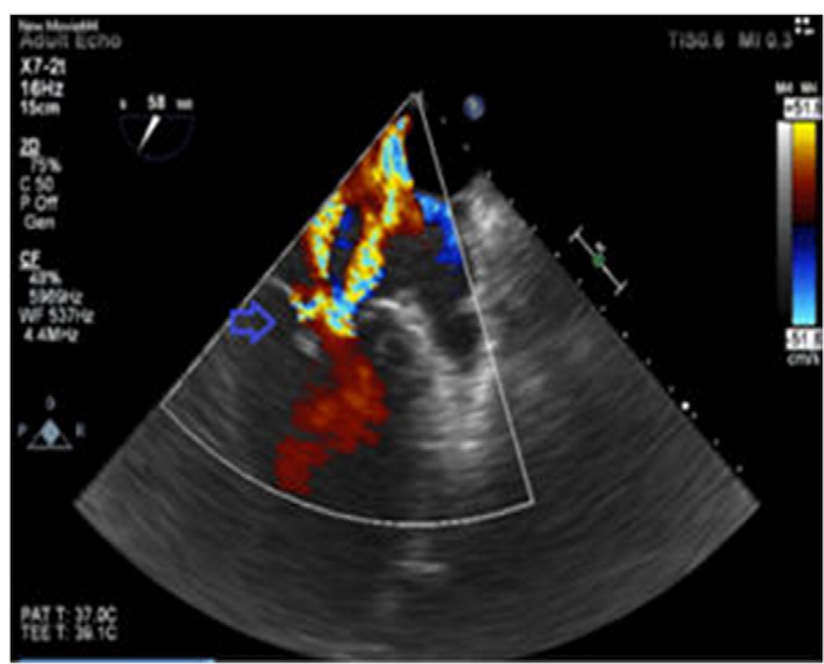

Fig. 3. A perforation due to the destruction of the vegetation which causes a second jet on the anterior leaflet of the mitral valve was observed in addition to the severe central mitral insufficiency.

stability of the patient dramatically deteriorated and died despite sufficient inotropic support treatment.

\section{Discussion}

Coexistence of hemodialysis and infective endocarditis is an issue which is known for a long time. Although the cause of the increase in IE prevalence is multifactorial, the most important mechanism is catheter-related endocardial damage and catheter infection. Although HD catheter-related right sided endocarditis is relatively common, left-sided endocarditis is quite rare. Venous catheter-related left valve endocarditis occurs due to the septicemic spread of catheter infection or the left sided valves' direct involvement as in our case due to the malposition of the catheter. HD catheter's left sided location by passing from the iatrogenic or congenital defects in IAS and leading to IE is a very rare condition. This condition usually occurs during the procedures which are conducted without using imaging method or echocardiography. In our case, HD catheter which was inserted through the subclavian vein without using an imaging method was located in the left atrium and left-sided endocarditis developed.

There is not an accurate treatment method in the catheter-related left-sided endocarditis as it is a rare condition. General approach is the combination of medical and surgical treatment. Timing of surgery should be done according to the clinical condition of the patient. ${ }^{4}$

In the cases without heart failure, proper antibiotic treatment may be followed by elective surgery. Early surgery is the most proper approach in the patients who have severe heart failure together with severe valve insufficiency, as in our case. Mortality rate is very high in HD catheter-related endocarditis. Mc Carthy et al. found one month mortality around $29 \%$ in this group of patients. ${ }^{4}$ Perioperative mortality was detected as $73 \%$ in these patients. ${ }^{5}$ A proper antibiotic treatment was applied after the diagnosis had been made and early surgery was planned however the patient died before the operation due to the sudden impairment of his clinical condition.

Endocarditis should be suggested in the HD patients who were admitted with complaints of fever and dyspnea and location of the catheter and presence of a vegetation should be carefully detected with echocardiography. The location of the catheter should certainly be verified with an imaging method during or after the procedure in order to avoid from the complications of malposition and asepsis measures and antibiotic prophylaxis should be considered. 


\section{References}

1. Abbott KC, Agodoa LY. Hospitalizations for bacterial endocarditis after initiation of chronic dialysis in the United States. Nephron 2002;91:203-209.

2. Powe NR, Jaar B, Furth SL, Hermann J, Briggs W. Septicemia in dialysis patients: incidence, risk factors, and prognosis. Kidney Int. 1999;55:1081-1090.

3. Chrissoheris MP, Libertin C, Ali RG, Ghantous A, Bekui A, Donohue T. Endocarditis complicating central venous catheter bloodstream infections: a unique form of health care associated endocarditis. Clin. Cardiol. 2009;32:48-54.
4. McCarthy JT, Steckelberg JM. Infective endocarditis in patients receiving long-term hemodialysis. Mayo Clin. Proc. 2000;75:1008-1014.

5. Spies C, Madison JR, Schatz IJ. Infective endocarditis in patients with end-stage renal disease: clinical presentation and outcome. Arch. Intern. Med. 2004;164:71-75. 